\title{
Academie of periferie? Waardering door de leerling
}

\author{
K. Boor, F. Scheele, H.A.M. Brölmann, J.Th.M. van der Schoot, L.F.J. van der Velden, P.J. Dorr
}

\section{Samenvatting}

Inleiding: De opleiding van basisartsen en medisch specialisten vindt zowel in universitaire klinieken als perifere opleidingsziekenhuizen plaats. In dit artikel is onderzocht of er een verschil bestaat tussen academische en niet-academische centra in de waardering van onderwijsitems.

Methode: Hiertoe zijn twee groepen onderzocht. Allereerst de co-assistenten ( $n=90)$ die middels een enquête hun mening gaven over het ervaren onderwijsklimaat tijdens hun co-schap gynaecologie en verloskunde. Daarnaast is (voormalige) agio's verloskunde en gynaecologie $(n=326)$ gevraagd waar zij de meeste vaardigheden en kennis hebben opgedaan.

Resultaten: De co-assistenten vonden het onderwijsklimaat in de periferie beter dan in de academie ( $p<0.05)$. Agio's en pas afgestudeerde gynaecologen deden vaardigheden en kennis het meest op in niet-academische ziekenhuizen $(p<0.05)$.

Discussie en conclusies: Oorzaken voor deze uitkomsten worden gezocht in (1) de beperkte prioriteit die de medische opleiding in academische ziekenhuizen krijgt en in (2) veranderende patiëntenstromen die het onderwijsklimaat benadelen. Er wordt voor gepleit om academische en niet-academische ziekenhuizen verder te laten integreren om de verschillende taken als onderwijs en onderzoek optimaal te laten vervullen. Daarbij is een herwaardering nodig van diegenen die zich sterk inspannen ten behoeve van de medische opleiding. (Boor $K$, Scheele $F$, Brölmann HAM, Schoot JThM van der, Velden LFJ van der, Dorr PJ. Academie of periferie? Waardering door de leerling. Tijdschrift voor Medisch Onderwijs 2005;24(2):87-94.)

\section{Inleiding}

In de meeste artsopleidingen in ons land is een structuur herkenbaar van prekliniek en kliniek (co-schappen). De preklinische fase wordt voor het leeuwendeel verzorgd door academisch werkende professionals. De klinische fase van de artsopleiding verschuift langzaam maar zeker naar de grote niet-academische opleidingsziekenhuizen. Zowel het aantal co-assistenten als het aantal medisch specialisten in opleiding (agio's) zal moeten toenemen. ${ }^{1}$ Voor de coschappen geldt dat die in de komende jaren voor meer dan de helft in niet-academische ziekenhuizen worden verzorgd. Ook bij meerdere specialistenopleidingen is een trend zichtbaar om de opleidingstijd in de niet-academische opleidingsziekenhuizen te verlengen ten koste van de tijd die wordt doorgebracht in academische klinieken.

De diversiteit in het ervaren onderwijsklimaat is groot. In eerder verrichtte studies blijkt dat er significante verschillen bestaan tussen verschillende specialismen als het gaat om hun houding tegenover onderwijs, de toegankelijkheid van supervisie, sociale verhoudingen en de variëteit aan leermogelijkheden. ${ }^{2}$ Het onderwijsklimaat heeft invloed op wat mensen leren en wordt tegenwoordig van groot belang geacht voor goed onderwijs..$^{3-6}$ Onder andere in Australië is gebleken dat kleinere opleidingsziekenhuizen een effectiever onderwijsklimaat hebben dan grotere (universi- 
taire) centra. Deze grotere centra hebben weliswaar meer mogelijkheden, maar zijn weinig toegespitst op de behoeften van jonge dokters. $^{7}$

Om te bekijken of er verschillen bestaan tussen het onderwijsklimaat in perifere en universitaire klinieken in Nederland zijn er in 2003 en begin 2004 metingen gedaan onder co-assistenten en (voormalige) agio's in de verloskunde en gynaecologie. Er is bekeken of de eerder in het buitenland gevonden bevinding dat de periferie een beter onderwijsklimaat weet te scheppen, ook hier te staven is met wetenschappelijk onderzoek.

\section{Methode}

Voor de meting van de ervaren kwaliteit van de medische vervolgopleiding zijn twee groepen bekeken. Zowel de mening van co-assistenten over de co-schappen als de mening van agio's en recent opgeleide gynaecologen over de specialistenopleiding zijn onderzocht.

\section{De co-schappen verloskunde en gynaecologie}

Onder de co-assistenten is onderzoek gedaan naar hun mening betreffende het onderwijsklimaat. Hiervoor is de gevalideerde Postgraduate Hospital Educational Environment Measure (PHEEM) uit Dundee gebruikt (tabel 1). ${ }^{8}$ De PHEEM meet 3 aspecten van het klinische onderwijsklimaat: het onderwijs zelf, de mogelijkheid tot autonoom functioneren en de sociale ondersteuning. Elke stelling kan gescoord worden op een 5-puntsschaal, variërend van 'helemaal oneens' tot aan 'helemaal eens'. De enquête is uit het Engels in het Nederlands vertaald en vervolgens weer door een onafhankelijke persoon in het Engels. Hierna hebben de ontwerpers van de PHEEM die versie weer gecontroleerd en zij oordeelden dat de tweede Engelse versie goed leek op de eerste.

In 2003 en begin 2004 zijn in 3 universiteitsklinieken (AMC, AZVU, LUMC) en 3 perifere klinieken (MCA, SLAZ, Bronovo ziekenhuis) vragenlijsten aan co-assistenten

Tabel 1. De PHEEM-enquête.

Mogelijkheid tot
autonoom functioneren Ik heb een overzichtelijk rooster met tijden van werk en diensten.
4. Er is een informatieve introductie bij dit co-schap.
5. Ik heb een passend niveau van verantwoordelijkheid in dit co-schap.
8. Ik moet ongepaste arbeid vervullen.
9. Er is een geschikte handleiding voor dit co-schap.
11. Ik word voor onterechte zaken opgepiept.
14. Er zijn duidelijke klinische protocollen aanwezig in dit co-schap.
17. Men zet mij hier in conform de landelijke ontwikkelingen aangaande
werktijdenregelingen voor co-assistenten.
18. Ik krijg de gelegenheid om mijn patiënten te vervolgen.
29. Ik ben in dit co-schap onderdeel van een team.
30. Ik krijg in dit co-schap voldoende kans om praktische vaardigheden op
te doen.
32. De werkbelasting in dit co-schap is goed.
34. Dit co-schap bereidt mij goed voor als basisarts.
40. De opleiders stimuleren een sfeer van wederzijds respect..


Vervolg tabel 1

Sociale ondersteuning 7. Er is sprake van rassendiscriminatie in dit co-schap.

13. Er is sprake van een seksuele discriminatie in dit co-schap.

16. $\mathrm{Er}$ is goede samenwerking tussen de co-assistenten.

19. Ik kan tijdens dit co-schap adviezen over mijn verdere carrière krijgen.

20. Het ziekenhuis heeft goede accommodatie/slaapkamer voor coassistenten, vooral voor tijdens diensten.

24. Ik maak me geen zorgen over mijn gezondheid in dit ziekenhuis.

25. Er heerst hier geen verwijt-cultuur.

26. Tijdens de diensten is er adequate maaltijdvoorziening.

35. Mijn klinische docenten zijn goede mentoren.

36. Ik werk bij dit co-schap met plezier.

38. Er is een goede begeleiding van co-assistenten die onvoldoende functioneren.

\section{Onderwijs}

2. Mijn klinische docenten maken goed duidelijk wat van mij verwacht wordt.

3. Er is beschermde tijd voor onderwijs in dit co-schap.

6. Er is altijd goede klinische supervisie.

10. Mijn opleiders/docenten hebben goede communicatievaardigheden.

12. Ik kan actief deelnemen aan onderwijsactiviteiten.

15. Mijn klinische docenten zijn enthousiast.

21. Ik krijg hier het onderwijsprogramma waar ik behoefte aan heb.

22. Ik krijg regelmatig feedback van de artsen.

23. Mijn klinische docenten zijn goed georganiseerd.

27. Er zijn voor mij genoeg leermomenten tijdens dit co-schap.

28. De klinische docenten hebben goede onderwijsvaardigheden.

31. Mijn opleiders/docenten zijn toegankelijk.

33. De staf gebruikt momenten waar je wat van kunt leren effectief.

37. Mijn klinische docenten stimuleren mij om zelfstandig te studeren/leren.

39. De opleiders/docenten geven mij goede feedback over mijn sterke en zwakke kanten.

De originele, uitgedeelde enquête is niet opgesplitst in deze categorieën maar loopt van 1 tot 40 (voor dit artikel is deze vorm gekozen om te verhelderen welke stelling bij welk subonderdeel hoort). De gecursiveerde items werden in de analyse achteraf 'omgekeerd' beoordeeld, dat wil zeggen: wanneer er bijvoorbeeld 'helemaal eens' ingevuld werd, werd deze verwerkt alsof er 'helemaal oneens' stond.

uitgedeeld. Alleen co-assistenten in de tweede helft van hun co-schap zijn geïncludeerd. Voor deze steekproef zijn de eerste 15 ingevulde enquêtes per kliniek gebruikt voor het onderzoek. Voor de statistische bewerking van de PHEEM werd gebruik gemaakt van de dubbelzijdige t-toets voor ongepaarde waarnemingen. Om de waarde van de gevonden verschillen te duiden zijn nog twee extra statistische beoordelingen verricht. Ten eerste is Cronbach's alpha berekend om de mate van samenhang tussen de verschil- 
lende items te controleren. Ook Cohen's d is bepaald. Deze waarde geeft weer hoe groot de verschillen zijn tussen beide gemiddelden ten opzichte van de standaarddeviatie. ${ }^{9}$

\section{De opleiding tot gynaecoloog}

In 2003 is voor de specialistenopleiding geënquêteerd met 4 door de commissie Onderwijs van de Nederlandse Vereniging voor Obstetrie en Gynaecologie (NVOG) geformuleerde vragen. Deze waren opgenomen in een enquête van het NIVEL in opdracht van het bestuur van de NVOG. Aan zowel agio's als recent opgeleide gynaecologen is gevraagd om aan te geven in welke mate men kennis en vaardigheden heeft ontleend aan de universitaire opleiding. Aan dezelfde groep zijn tegelijkertijd overeenkomstige vragen gesteld over de perifere opleiding. Elke stelling kan gescoord worden op een 5-puntsschaal, variërend van 'helemaal oneens' tot aan 'helemaal eens'. Voor het beoordelen van de antwoorden over de opleiding tot gynaecoloog, is gebruik gemaakt van een dubbelzijdige t-toets voor gepaarde waarnemingen. De significantiegrens is op 0.05 gesteld. Ook hier is Cohen's d berekend. Berekeningen vonden plaats met behulp van SPSS.

\section{Resultaten}

\section{De co-schappen verloskunde en gynaecologie}

45 respondenten van 3 niet-academische ziekenhuizen en 45 respondenten van 3 academische ziekenhuizen zijn vergeleken. Elk item is apart gescoord. De score 'helemaal oneens' is gelijk gesteld aan 0, de score 'helemaal eens' is gelijk gesteld aan 4. Naast de scores zijn de standaarddeviaties van beide groepen weergegeven. Alle uitkomsten zijn statistisch significant. De score op de PHEEM van de academische klinieken versus de niet-academische klinieken is voor het totaal 115 versus 128 ( $\mathrm{p}<0.05$; SDacademie 15.0, SDperiferie 14.4) en voor de deelaspecten 'onderwijs' 43 versus 48 ( $\mathrm{p}<0.05$; SDacademie 7.1, SDperiferie 6.9), 'autonome rol' 41 versus $44(\mathrm{p}<0.05$; SDacademie 6.3, SDperiferie 5.8) en 'sociale ondersteuning' 31 versus $36(\mathrm{p}<0.05$; Sdacademie 4.4, SDperiferie 3.7) (figuur 1).

De Cronbach's alpha voor de totale score op de PHEEM is 0.91 (wat duidt op een hoge homogeniteit van de vragenlijst). De Cronbach's alpha voor de respectievelijke categorieën is: onderwijs 0.89 , autonome rol 0.78 en sociale ondersteuning 0.68 . De Cohen's d voor de totale score is 0.86 (wat duidt op een groot verschil). De respectievelijke categorieën behaalden de volgende Cohen's d: onderwijs 0.71 (middelgroot verschil), autonome rol 0.5 (middelgroot verschil) en sociale ondersteuning 1.14 (groot verschil).

\section{De opleiding tot gynaecoloog}

De eerste ondervraagde groep bestaat uit 248 agio's die begin 2003 in opleiding wa-

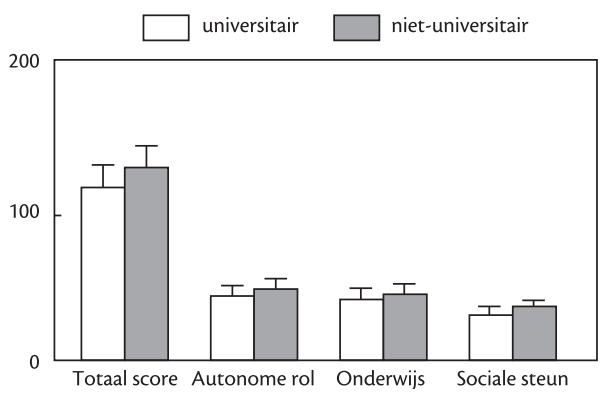

Figuur 1. De resultaten van de uit Dundee afkomstige PHEEM-enquête waarin het onderwijsklimaat gemeten wordt van 90 co-assistenten. Onderscheiden worden op de $x$-as de aspecten 'totaal score', de mogelijkheid een 'autonome rol' te vervullen, 'onderwijs' en 'sociale ondersteuning'. Op de y-as zijn totaalscores en standaarddeviaties vermeld. Er wordt een vergelijking gemaakt tussen universitaire klinieken en niet-universitaire klinieken. De gemeten verschillen zijn statistisch significant $(p<0.05)$. 
ren. Hiervan hebben 169 agio's de vragen volledig ingevuld (respons 68\%). De score 'helemaal oneens' is gelijk gesteld aan 0 , de score 'helemaal eens' is gelijk gesteld aan 4. Naast de gemiddelde scores zijn de standaarddeviaties weergegeven.

Op de vraag waar de huidige kennis opgedaan was, is voor de bijdrage van de periferie een gemiddelde score van 2.75 (SD: 0.9) gehaald, terwijl deze score voor de universitaire opleiding gemiddeld 2.25 (SD: 1.1) bedraagt; deze uitkomsten zijn statistisch significant $(\mathrm{p}<0.05)$. De Cohen's $\mathrm{d}$ bedraagt 0.56 (middelgroot verschil). Op de vraag waar de huidige vaardigheid opgedaan is, zijn respectievelijk scores van 3.17 (SD: 0.9) en 1.62 (SD: 1.1) gevonden; ook deze getallen zijn statistisch significant $(\mathrm{p}<0.05)$ (figuur 2). De Cohen's $\mathrm{d}$ is 1.72 (groot verschil).

De tweede ondervraagde groep bestond uit 197 gynaecologen die in 1997 nog in Nederland in opleiding waren, maar in 2003 inmiddels de opleiding hadden afgerond. Daarvan hebben 153 alle hier behandelde vragen ingevuld (repons 78\%). Alle resultaten zijn statistisch significant. Op de vraag naar waar relevante kennis opgedaan is, is voor de bijdrage van de periferie een gemiddelde score van 2.84 (SD: 0.8 ) vastgesteld, tegenover een score van 2.53 (SD: 0.9) voor de universitaire klinieken $(\mathrm{p}<0.05)$. De Cohen's d is 0.34 (klein verschil). Op de vraag waar relevante vaardigheid opgedaan is, zijn respectievelijk scores van 3.31(SD: 0.7) en 1.90 (SD: 1.1) behaald $(\mathrm{p}<0.05)$ (figuur 2). De Cohen's d bedraagt 2.0 (groot verschil).

\section{Discussie en conclusies}

Beide studies laten een hogere waardering zien voor niet-academische ziekenhuizen op verschillende onderdelen van het leerproces. De co-assistenten ervaren een beter onderwijsklimaat, de agio's geven aan

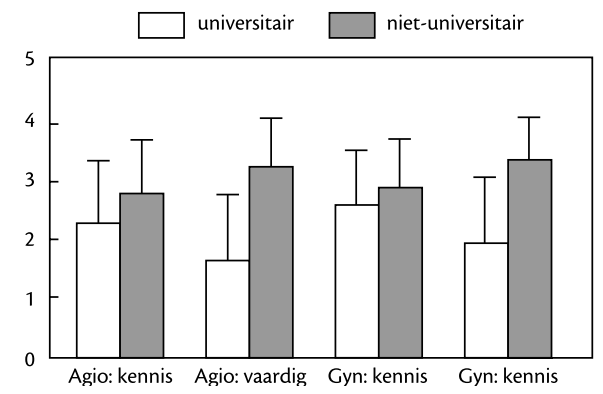

Figuur 2. Op de $x$-as staan de meningen van 168 agio's obstetrie en verloskunde en 153 net begonnen gynaecologen met betrekking tot waar zij hun huidige kennis en vaardigheden hebben opgedaan. Hierbij worden universitaire en niet-universitaire klinieken met elkaar vergeleken. Op de y-as wordt het gemiddelde en de standaarddeviatie weergegeven. De waargenomen verschillen zijn statistisch significant $(p<0.05)$.

de meeste relevante kennis en vaardigheden opgedaan te hebben in de periferie.

Verschillende kanttekeningen zijn te plaatsen bij deze uitkomsten. Ten eerste is er met name bij het onderzoek onder de co-assistenten sprake van een kleine steekproef. De huidige cijfers zijn wel significant (alle uitkomsten $\mathrm{p}<0.05$ ), eenduidig (Cronbach's alpha variërend van 0.68 tot 0.92 ) en in (middel)grote mate verschillend (Cohen's $\mathrm{d}$ in alle gevallen behalve een, groter dan 0.5). Extrapolatie van deze uitkomsten naar andere klinieken en disciplines vraagt echter om voorzichtigheid.

Verder is in deze studie niet onderzocht in hoeverre studenten bewust voor een academisch dan wel perifeer opleidingsziekenhuis hebben gekozen. Indien een student uitdrukkelijk verzocht heeft geplaatst te worden in een bepaald ziekenhuis, kan dit de uitkomst van de enquête uiteraard beïnvloeden.

Daarnaast is het van belang dat het onderzoeksinstrument, de PHEEM, alleen in Engeland gevalideerd is. De kenmerken van een goed onderwijsklimaat lijken echter op het oog ook op de Nederlandse 
situatie toepasbaar. Een uitgebreidere validatie wordt in gang gezet.

De onderzoeksvragen aan agio's en recent opgeleide gynaecologen ontlenen hun validiteit slechts aan een beperkt aantal onderwijsgeïnteresseerde gynaecologen.

Tenslotte kun je met dit beschrijvende onderzoek niet stellen dat met deze uitkomsten het onderwijs in perifere klinieken ook beter is. Bij de studie onder de co-assistenten lijkt het wel waarschijnlijk dat met een beter onderwijsklimaat er ook beter geleerd wordt, echter dat is niet onderzocht in deze studie. In het onderzoek onder agio's is gekeken naar vaardigheden en kennis; dat deze minder worden opgedaan in een universitaire kliniek wil nog niet zeggen dat deze opleiding minder goed is.

Desondanks geven de bevindingen een duidelijk signaal: de ervaren kwaliteit van het onderwijsklimaat scoort hoger voor perifere ziekenhuizen. Over de meer inhoudelijke redenen voor deze uitkomst kan worden gespeculeerd.

Wanneer er gekeken wordt naar de prioriteit die de medische opleiding op de universitaire werkvloer heeft, ontstaat de indruk dat de academisch werkende specialist in eerste instantie wordt afgerekend op wetenschappelijk onderzoek en in tweede instantie op patiëntenzorg. Onderwijs heeft relatief geringe status. ${ }^{10}$ Het zich profileren op onderwijs resulteert niet vaak in een hoogleraarschap. ${ }^{10}$ Enigszins chargerend kan men stellen dat om carrière te maken in de academische kliniek, het noodzakelijk is om zich te concentreren op wetenschappelijk onderzoek. Verder bekommert men zich veelal om die typen patiëntenzorg, die passen in de lijn van wetenschappelijk onderzoek. De complexiteit van de zorgvraag binnen de academie verhindert grote aantallen patiënten. Dit probleem wat betreft de waardering van onderwijsinspanning speelt in meerdere landen en er zijn in de literatuur meerdere interessante ideeën te vinden om onderwijsinspanning wel zichtbaar te maken. ${ }^{11-13}$ Deze literatuur laat zien dat het loopbaanperspectief een van de krachtigste instrumenten is om meer aandacht van de academisch werkzame specialist voor onderwijs te verkrijgen en academisch leiderschap te stimuleren. Academisch leiderschap kan ook van groot belang blijken voor onderwijsprofessionalisering in de medische staven. Gelukkig zijn er een aantal voorbeeldige initiatieven op dit gebied aan te wijzen. ${ }^{14-}$ ${ }^{15}$ In de niet-academische opleidingsziekenhuizen heeft patiëntenzorg voor grote aantallen patiënten de eerste aandacht en is onderwijs daarna de evidente tweede in de prioriteitstelling. Wil men in de perifere ziekenhuizen de huidige aandacht voor het onderwijs vasthouden, dan moet ook hier de waardering voor onderwijsinspanning duidelijk zijn.

Een tweede mogelijke oorzaak is het eerder genoemde verschil in zorgcomplexiteit. In academische klinieken zijn steeds meer bepaalde zeldzame zorgtypes geconcentreerd, die voor wetenschappelijk onderzoek en voor de derde lijn patiëntenzorgfunctie heel belangrijk zijn. In hoeverre dit soort patiënten geschikt is voor onderwijs aan studenten, die immers vooral kennis over vaker voorkomende ziekten moeten verkrijgen, is te betwijfelen. Recent onderzoek onder co-assistenten heelkunde in een academisch ziekenhuis toont aan dat de expositie aan verschillende patiëntproblemen onvoldoende is. ${ }^{16}$ Overigens is de mogelijkheid om veel actieve patiëntcontacten te hebben op zichzelf niet voldoende om een leerzaam co-schap te hebben. De waarde van de actieve patiëntcontacten stijgt in belangrijke mate door directe observatie en construc- 
tieve feedback door begeleiders in een positief leerklimaat met gestructureerde onderwijsmomenten. ${ }^{17}$ Hoe dan ook lijkt het erop dat bij het concentreren van zeldzame en voor wetenschappelijk onderzoek interessante zorgtypes, de voor het onderwijs meer geschikte patiëntengroep gedeeltelijk is afgestoten. In geval van eerste prioriteit voor onderwijs zou hier niet snel voor gekozen zijn.

Is er een probleem? Ja, onderwijs lijkt door de academische wereld te worden ondergewaardeerd en de term hoogleraar dreigt daardoor in meerdere gevallen misleidend te worden. De hoogleraar blijkt nogal eens aan andere zaken prioriteit te geven dan klinisch onderwijs en is wat dat betreft vaak in de laatste plaats leraar.

Liggen er kansen? Zeker, wanneer de academische en niet-academische ziekenhuizen tot ruimere integratie komen op onder andere het terrein van onderwijs en onderzoek, dan ligt een symbiose voor de hand. Het accent voor opleiding en klinisch onderwijs lijkt te verschuiven naar de niet-academische opleidingsziekenhuizen en die moeten hun verantwoordelijkheid nemen. Terwijl de niet-academische opleidingsziekenhuizen met hun grote stromen patiënten het academische wetenschappelijke onderzoek beter kunnen ondersteunen, kunnen academische klinieken die de onderwijsgeldkraan beheren de niet-academische opleidingsklinieken ondersteunen in hun verder te professionaliseren rol voor onderwijs en opleiding. Met de verwachte uitbreiding en herstructurering van zowel de artsopleiding als de vervolgopleidingen ligt er een grote opdracht voor de al of niet academische ziekenhuizen. ${ }^{1}$ Hokjesgeest is hier contraproductief en samenwerking tussen de verschillende typen ziekenhuizen het toverwoord.

\section{Dankwoord}

Hierbij danken de auteurs dr. M. Sinaasappel, klinisch fysicus IO, voor diens hulp bij de statistische analyse en mw. dr. C.R.M.G. Fluit, arts-onderwijskundige, voor haar kritische maar zeer opbouwende commentaren op het manuscript.

\section{Literatuur}

1. Ministerie van Volksgezondheid, Welzijn en Sport. Zorg voor opleidingen en beroepen noodzaak voor toekomst [document op internet]. Den Haag: Ministerie van VWS [geciteerd op 14 maart 2005]. Beschikbaar op: www.minvws.nl/images/2416675_ tcm10-41926.pdf.

2. Patel VL, Dauphine WD. The clinical learning environment in medicine, paediatrics and surgery clerkships. Med Educ 1985;19:54-60.

3. Hutchinson L. Educational environment. BMJ 2003;326:810-2.

4. Ramdsen P. Learning to teach in higher education. London: Routledge; 1992.

5. Genn J, Harden RM. What is medical education here really like? Suggestions for action research studies of climates of medical education environments. Med Teach 1986;8(2):111-24.

6. Rotem A, Bloomfield L, Southon G. The clinical learning environment. Isr J Med Sci 1996;32:705-10.

7. Rotem A, Godwin P, Du J. Learning in hospital settings. Teach Learn Med 1995;7(4):211-7.

8. Roff S, McAleer S, Skinner A. Development and validation of an instrument to measure the postgraduate clinical learning and teaching environment for hospital-based doctors in the UK. Med Teach. In press 2005.

9. Cohen J. Statistical power analysis for the behavioral sciences. 2nd ed. New Jersey: Lawrence Erlbaum; 1988.

10. DeAngelis CD. Professors not professing. JAMA 2004;292:1060-1.

11. Levinson W, Rubinstein A. Mission critical -- integrating clinical-educators into academic medical centers. N Engl J Med 1999;341:840-3.

12. Sachdeva AK, Cohen R, Dayton MT, Herbert JC, Jamieson C, Neuma LA, et al. A new model for recognizing and rewarding the educational accomplishments of surgery faculty. Acad Med 1999;74:1278-87.

13. Sherertz EF. Criteria of the "educators pyramid" fulfilled by medical school faculty promoted on a teaching pathway. Acad Med 2000;75:954-6.

14. Borleffs JCC, Erkelens DW. Oog voor de toekomst, het geneeskundig onderwijs in de 21ste eeuw. Medisch Contact 2001;56(4):144-7. 
15. Borleffs JCC, Cate ThJ ten, Bruijnzeel-Koomen CAFM. Pleidooi voor een stage klinische onderwijskunde binnen de specialistische opleiding. Tijdschrift voor Medisch Onderwijs 2001;21:25-32.

16. Hem-Stokroos HJ van der, Scherpbier AJJA, Vleuten CPM van der, Vries H de, Haarman HJThM. How effective is a clerkship as a learning environment. Med Teach 2001;23:599-604.

17. Hem-Stokroos HJ van der, Daelmans HEM, Vleuten CPM van der, Haarman HJThM, Scherpbier AJJA. A qualitative study of clinical learning experiences. Med Teach 2003;25:120-6.

\section{De auteurs:}

Drs. K. Boor is arts en werkzaam in het Sint Lucas Andreas Ziekenhuis te Amsterdam.
Prof. dr. F. Scheele is als hoogleraar Obstetrie en Gynaecologie verbonden aan het Sint Lucas Andreas Ziekenhuis/VUmc te Amsterdam.

Prof. dr. H.A.M. Brölmann is als hoogleraar Obstetrie en Gynaecologie verbonden aan het VUmc te Amsterdam. Dr. J.Th.M. van der Schoot is gynaecoloog en werkzaam in het Sint Lucas Andreas Ziekenhuis te Amsterdam. Dr. L.F.J. van der Velden is verbonden aan de Staf Nivel. Dr. P.J. Dorr is gynaecoloog en werkzaam in het Westeinde Ziekenhuis te Den Haag.

Correspondentieadres:

Prof. dr. Fedde Scheele, Sint Lucas Andreas Ziekenhuis, Jan Tooropstraat 164, 1061AE Amsterdam, tel: 0205108911 (sein 395),f.scheele@slaz.nl.

\section{Summary}

Introduction: (Junior-) doctors are trained in both university and affiliated district hospitals. This article describes two studies examining potential differences between these two types of hospital in education-related aspects.

Method: The two studies were conducted in the field of Obstetrics and Gynaecology. The first study sought junior doctors' ( $n=90$ ) opinions about their educational environment. The second study evaluated in which setting (university or affiliated district hospital) specialist registrars who were in their final year of training or had recently completed their training (n=326) had gained the most knowledge and practical skills.

Results: The results show that junior doctors perceived district hospitals as offering a better learning environment compared with university hospitals $(p<0.05)$. The specialist registrars who participated in the second study favoured the affiliated hospitals on both aspects studied $(p<0.05)$.

Discussion and conclusions: Possible explanations for these findings are: (1) the moderate priority of medical education in university hospitals due to a rewarding system that is heavily weighted in favour of research and (2) the emphasis on highly specialised care for patients with rare diseases. The case is made for the integration of university and district hospitals for the purpose of enhancing their task fulfilment in both education and research. These collaborating hospitals should create the possibility for rewarding teaching efforts and offering promotion and career prospects on the basis of achievements in education. (Boor K, Scheele F, Brölmann HAM, Van der Schoot JThM, Van der Velden LFJ, Dorr PJ. University hospital or district hospital? The views of clinical clerks. Dutch Journal of Medical Education 2005;24(2):87-94.) 